\title{
PARAMETRII MORFOMETRICI AI SPECIEI ACANTHOCEPHALUS RANAE SCHRANK, 1788 (ACANTHOCEPHALA) DEPISTATĂ LA SPECIMENELE COMPLEXULUI PELOPHYLAX ESCULENTA (AMPHIBIA)
}

https://doi.org/10.53937/9789975315975.39

\section{Erhan Dumitru, Gherasim Elena}

Institutul de Zoologie al Ministerului Educației, Culturii și Cercetării, Chișinău, R. Moldova

\section{E-mail:gherasimlenuta@gmail.com}

\begin{abstract}
The article describes the results of the parasitological investigations of Pelophylax esculenta complex (Amphibia). A total number of 360 individuals have been subjects of parasitological study. A new species of Acanthocephala for the Republic of Moldova have been identified - Acanthocephalus ranae. In the paper there are presented the results regarding the infestation of complex Pelophylax esculenta by the acanthocephala species from Echinorhynchidae. For each species there were established: taxonomic status, including the hosts, the location in organs, the geographic spreading, etiology and biologic cycle. There are also mentioned the amount of collected material, the morphologic description of the species, original figures and pictures.
\end{abstract}

Key words: Pelophylax esculenta complex (Amphibia), Acanthocephala, water reservoir.

\section{INTRODUCERE}

Atât în Republica Moldova, cât și în alte regiuni ale lumii, amfibienii, în special anurele, sunt răspândite în majoritatea habitatelor naturale. Amfibienii ecaudaţi sunt gazdele unei game largi de paraziţi, care fac parte din ecosistemele acvatice. Atât amfibienii, cât și fauna lor parazitară, sunt purtători de informaţii despre starea ecosistemului în ansamblu $[3,5,7]$.

Parazitofauna și diversitatea ei ca parte componentă a ecosistemelor acvatice, este unul din principalii factori biotici, care determină numeric speciile-gazdă, iar prin reglarea numerică a gazdelor se influențează și asupra structurii și funcționării acestor ecosisteme în întregime. Asupra modului de comportament al amfibienilor, așa ca perioada de aflare 
a lor în mediul acvatic s-au terestru, dependența de biotop și factorii trofici este influențată și de extensivitatea și intensivitatea invaziei cu helminți, precum și de specificitatea lor [7].

Helminții ce aparțin încrengăturii Achanthocephala afectează mamiferele domestice și sălbatice, păsările, peștii, amfibienii, iar în unele cazuri și omul. Sunt endoparaziți, relativ un grup nu mare de specii, circa 500. Ei sunt dioici, au corpul nesegmentat, iar la extremitatea anterioară prezintă o trompă protractilă cu spini sau croșete. Ciclul biologic este heteroxen.

La 197 de specii de animale vertebrate au fost înregistrate 55 de specii de acantocefali. La 32 specii de acantocefali dezvoltarea ciclului biologic depinde de mediul acvatic (hidrotopic). Aceștia sunt paraziții peștilor maritimi și ai apelor dulci și ai amfibienilor. 23 de specii de acantocefali sunt geotopici și sunt paraziți specifici amfibienilor, păsărilor terestre și ai mamiferelor. Ca gazde intermediare pentru toate speciile de acantocefali hidrotopici sunt crustaceele Ostracoda, Amphipoda și Isopoda acvatice, iar ca gazde intermediare pentru speciile de acantocefali geotopici sunt isopodele terestre și insectele (Coleoptera). La circuitul a 4 specii de acantocefali hidrotopici și 7 specii de acantocefali geotopici participă gazdele paratenice -, amfibienii, reptilele și mamiferele [1].

În Republica Moldova Andreico O. F. (1973) a stabilit 3 specii de acantocefali la rozătoare: Centrorhynchus sp. din fam. Giganthorhynchidae și Moniliformis moniliformis Bremser, 1811 și Moniliformis sp. din fam. Moniliformidae. Acantocefalii la animale sunt înregistrați foarte rar și din acest motiv practic este imposibil de a stabili frecvența răspândirii lor la diferite specii de animale în Republica Moldova [2].

La amfibienii complexului Pelophylax esculenta (Pelophylax ridibundus, Pelophylax lessonae, Pelophylax esculentus) din ecosistemele naturale și antropizate ale Codrilor Centrali din Republica Moldova s-au 
stabilit mai multe specii de acantocefali hidrotopici dintre care și specia Acanthocephalus ranae, Schrank, 1788.

\section{MATERIAL ȘI METODE}

Cercetările helmintologice s-au efectuat conform metodei standart, propusă de K.I. Skrjabin, care implică examinarea tuturor organelor interne ale animalului [8].

Colectarea, fixarea și prelucrarea materialului s-a efectuat după metodele propuse de Petrocenco [1]. Se taie o porțiune din peretele intestinului de care este atașată acantocefala și se transferă într-o cutie Petri, peste care se picură apă. După aceasta, atent, cu ajutorul acului de preparare, se eliberează trompa de porțiunea intestinală a gazdei. După eliberarea trompei, se spală întreg parazitul prin apă pentru înlăturarea oricăror excremente și se fixează în alcool de $70^{\circ}$. La fixarea acantocefalelor, este necesar de a atrage atenţie asupra trompei cefalice, ca să fie complet scoasă și vizibile rândurile longitudinale de cârlige, pentru determinarea ulterioară a speciei $[4,6]$.Determinarea acanthocefalelor s-a efectuat după K. M. Râjikov ș. a. [5].

Specia Acanthocephalus ranae în număr de 86 de exemplare au fost obținute de la specia Pelophylax ridibundus colectată din lacurile nr. 1, 2 - Ciuciuleni, nr. 10 - Rezervația "Codrii”, din lacul de la mănăstirea Hâncu, Ghidighici și Valea Trandafirilor; P. lessonae - din lacurile nr. 2 Ciuciuleni, nr. 10, 11 - Rezervația "Codrii", lacul de la Mănăstirea Hâncu și Ghidighici, iar specia P.esculentus a fost colectată din lacul de la Mănăstirea Hâncu și lacul Ghidighici.

Pentru stabilirea veridicității datelor au fost folosite metode de analiză matematică și statistică prin utilizarea pachetului de programe BIOSTAT, versiunea 1.0 elaborat la Catedra de Zoologie a USM de către academicianul Ion Toderaș și Statistica Workbook 7, iar interpretarea schematică a rezultatelor obținute s-a efectuat utilizând programul CoreIDROW Graphics Suite X4. 
Morfologia acanthocephalelor s-a studiat pe baza preparatelor totale, la microscopul Novex Holland B. series cu obiectivul 20 și ocularul WF 10X DIN/20MM.

\section{REZULTATE ȘI DISCUȚII}

Toate speciile de acantocefali sunt endoparaziți, care provoacă boli și au o însemnătate practică, determinată prin acțiunea lor traumatică și spoliatoare asupra organismului gazdă, iar în unele cazuri și moartea lor [4]. La amfibienii complexului Pelophylax esculenta în intestinul subţire s-a stabilit prezenţa agenţilor parazitari din clasa Palaeacanthocephala, ordinul Echinorhynchida, familia Echinorhynchidae, genul Acanthocephalus cu specia Acanthocephalus ranae (Schrank, 1788).

Specia Acanthocephalus ranae Schrank, 1788 este răspândită în țările europene, asiatice și America de Nord și parazitează în intestinul subțire al amfibienilor (Foto 1).

Foto 1. Acanthocephalus ranae: aspectul general într-o porțiune de intestin subțire;

Corpul are suprafață netedă, formă cilindrică cu o ușoară extindere a capătului anterior.

Peretele corpului este protejat de o cuticulă subțire sub care se află 
hipodermul, care reprezintă o rețea complicată de canale lacunare - sistemul lacunar.

Corpul lor reprezintă două regiuni distincte: prosoma retractilă și trunchiul. Prosoma reprezintă un gât și o trompă sau proboscis înzestrat cu cârlige, cu rol de fixare. Numărul cârligelor au rol și taxonomic. Sexele sunt separate, iar din dimensiunile corporale ale masculilor și femelelor reiese dimorfismul sexual.

Masculul are lungimea corpului de - 6,836-12,150 mm și lățimea de 0,873-1,333 mm. (Figura 1, foto 2, tabelul 1). Proboscisul este scurt, cu forma ușor cilindrică și lungimea de 0,196-0,472 mm. Pe proboscis se află 16 rânduri longitudinale de cârlige. Fiecare rând longitudinal include câte 6 croșete. Primele 3 rânduri de croșete sunt ascuțite și au lungimea de 0,030-0,048;0,034-0,040;0,030-0,051 mm. Al patrulea rând de cârlige au lungimea de 0,035-0,062 mm, al cincilea rând - 0,030-0,064 mm, iar al șaselea - 0,023-0,066 mm. Rădăcinile de obicei au aceleași dimensiuni ca și cârligele, însă sunt mai groase. Spre deosebire de proboscis, gâtul are formă conică și dimensiuni mai mici - 0,159-0,284 x 0,264$0,438 \mathrm{~mm}$.

Cavitatea proboscisului are lungimea de 0,582-1,190 mm, iar lățimea de 0,249-0,531 mm. La joncțiunea dintre prosomă și trunchi se găsesc două invaginări numite lemnisci, cu lungimea de 0,687- 0,706 mm, iar lățimea pentru fiecare fiind de 0,219-0,230 mm.

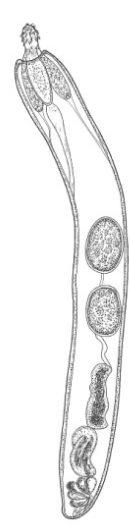

Fig. 1. Acanthocephalus ranae Schrank, 1788: mascul, aspectul general.

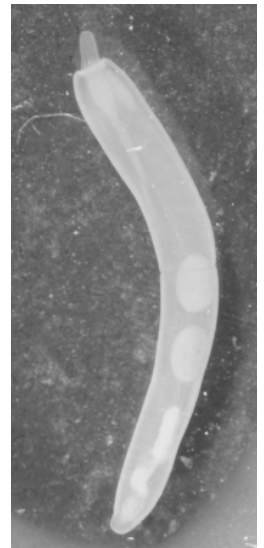

Foto 2. Acanthocephalus ranae, mascul. Original. 
În treimea mijlocie a corpului se află testiculele ovoide, testiculul anterior cu dimensiunea de 0,881-0,508 mm, este urmat de cel de-al doilea testicul cu dimensiunea de 0,817-0,494 mm. Posterior de testicule se află 6 glande compacte, iar orificiul genital este ușor subterminal (tabelul 1).

Tabelul 1. Parametrii morfometrici ai speciei Acanthocephalus ranae, masculi, $n=7$

\begin{tabular}{|l|l|l|l|l|l|l|l|}
\hline Caracterele & $\begin{array}{l}\text { Media, } \\
\mathrm{mm}\end{array}$ & MS & $\sigma$ & CV & sdCV & $\begin{array}{l}\text { Minim, } \\
\mathrm{mm}\end{array}$ & $\begin{array}{l}\text { Maxim, } \\
\mathrm{mm}\end{array}$ \\
\hline Suprafața & 0,801 & 1,208 & 3,197 & 39,9 & 12,2 & 4,833 & 13,950 \\
\hline Lungimea corpului & 8,835 & 0,728 & 1,926 & 21,8 & 6,1 & 6,836 & 12,150 \\
\hline Lățimea corpului & 1,070 & 0,075 & 0,184 & 17,2 & 5,1 & 0,873 & 1,333 \\
\hline Lungimea proboscisului & 0,345 & 0,045 & 0,100 & 28,9 & 9,9 & 0,196 & 0,472 \\
\hline Lățimea proboscisului & 0,272 & 0,023 & 0,051 & 18,9 & 6,2 & 0,238 & 0,361 \\
\hline Lungimea gâtului & 0,208 & 0,017 & 0,043 & 20,4 & 6,1 & 0,159 & 0,264 \\
\hline Lățimea gâtului & 0,321 & 0,024 & 0,058 & 18,1 & 5,4 & 0,284 & 0,438 \\
\hline Lungimea I-lui cârlig & 0,036 & 0,004 & 0,008 & 23,7 & 8,9 & 0,030 & 0,048 \\
\hline Lungimea al II-lea cârlig & 0,037 & 0,002 & 0,003 & 8,2 & 3,4 & 0,034 & 0,040 \\
\hline Lungimea al III-lea cârlig & 0,041 & 0,005 & 0,010 & 22,1 & 8,2 & 0,030 & 0,051 \\
\hline Lungimea al IV-lea cârlig & 0,044 & 0,006 & 0,012 & 28,2 & 10,7 & 0,035 & 0,062 \\
\hline Lungimea al V-lea cârlig & 0,038 & 0,006 & 0,014 & 37,4 & 13,4 & 0,030 & 0,064 \\
\hline Lungimea al VI-lea cârlig & 0,037 & 0,010 & 0,020 & 52,9 & 23,4 & 0,023 & 0,066 \\
\hline Lungimea cavității proboscisului & 0,801 & 0,084 & 0,221 & 27,3 & 7,8 & 0,582 & 1,190 \\
\hline Lățimea cavității proboscisului & 0,356 & 0,042 & 0,112 & 31,5 & 9,2 & 0,249 & 0,531 \\
\hline Lungimea lemniscului drept & 0,687 & 0,061 & 0,148 & 21,6 & 6,5 & 0,462 & 0,839 \\
\hline Lățimea lemniscului drept & 0,219 & 0,010 & 0,024 & 11,2 & 3,3 & 0,182 & 0,248 \\
\hline Lungimea lemniscului stâng & 0,706 & 0,055 & 0,109 & 15,5 & 5,6 & 0,598 & 0,856 \\
\hline Lățimea lemniscului stâng & 0,230 & 0,018 & 0,036 & 15,9 & 5,8 & 0,187 & 0,276 \\
\hline Lungimea testiculului anterior & 0,881 & 0,095 & 0,233 & 26,5 & 8,2 & 0,649 & 1,323 \\
\hline Lățimea testiculului anterior & 0,508 & 0,040 & 0,098 & 19,3 & 5,8 & 0,417 & 0,674 \\
\hline Lungimea testiculului posterior & 0,817 & 0,094 & 0,231 & 28,3 & 8,8 & 0,632 & 1,242 \\
\hline Lățimea testiculului posterior & 0,495 & 0,486 & 0,119 & 24,1 & 7,3 & 0,375 & 0,700 \\
\hline
\end{tabular}

Notă: MS - eroarea mediei, $\sigma$ - abaterea mediei pătratică, CV - coeficientul de variație, sdCV - eroarea coeficientului de variație 
Lungimea femelelor este mai mare decât cea a masculilor. Proboscisul este întocmai ca la masculi. Ouăle sunt subțiri, fusiforme și ușor curbate, a căror lungime este de 0,065-0,099 mm, iar lățimea - de 0,008-0,013 $\mathrm{mm}$. Ouăle au proeminențe lungi și înguste la poli (tabelul 2).

Tabelul 2. Parametrii morfometrici ai speciei Acanthocephalus ranae, femele, $n=7$

\begin{tabular}{|l|l|l|l|l|l|l|l|}
\hline Caracterele & $\begin{array}{l}\text { Media, } \\
\mathrm{mm}\end{array}$ & $\mathrm{MS}$ & $\sigma$ & $\mathrm{CV}$ & $\mathrm{sdCV}$ & $\begin{array}{l}\text { Minim, } \\
\mathrm{mm}\end{array}$ & $\begin{array}{l}\text { Maxim, } \\
\mathrm{mm}\end{array}$ \\
\hline Lungimea proboscisului & 0,404 & 0,029 & 0,066 & 16,3 & 5,3 & 0,326 & 0,473 \\
\hline Lățimea proboscisului & 0,305 & 0,024 & 0,055 & 17,9 & 5,8 & 0,241 & 0,362 \\
\hline Lungimea gâtului & 0,251 & 0,020 & 0,048 & 19,1 & 5,7 & 0,177 & 0,323 \\
\hline Lățimea gâtului & 0,341 & 0,028 & 0,069 & 20,1 & 6,0 & 0,284 & 0,429 \\
\hline Lungimea I-lui cârlig & 0,041 & 0,003 & 0,008 & 19,2 & 6,3 & 0,032 & 0,048 \\
\hline Lungimea al II-lea cârlig & 00042 & 0,004 & 0,008 & 19,8 & 6,5 & 0,034 & 0,056 \\
\hline Lungimea al III-lea cârlig & 0,052 & 0,003 & 0,007 & 13,5 & 4,4 & 0,042 & 0,060 \\
\hline Lungimea al IV-lea cârlig & 0,049 & 0,005 & 0,011 & 22,0 & 7,3 & 0,035 & 0,059 \\
\hline Lungimea al V-lea cârlig & 0,049 & 0,007 & 0,015 & 29,6 & 10,1 & 0,032 & 0,061 \\
\hline Lungimea al VI-lea cârlig & 0,048 & 0,007 & 0,016 & 33,0 & 11,5 & 0,024 & 0,062 \\
\hline Lungimea cavității proboscisului & 0,875 & 0,097 & 0,258 & 29,5 & 8,5 & 0,582 & 1,187 \\
\hline Lățimea cavității proboscisului & 0,388 & 0,047 & 0,125 & 32,3 & 9,5 & 0,249 & 0,528 \\
\hline Lungimea lemniscului drept & 0,734 & 0,048 & 0,118 & 16,1 & 4,8 & 0,552 & 0,840 \\
\hline Lățimea lemniscului drept & 0,224 & 0,011 & 0,027 & 12,0 & 3,5 & 0,182 & 0,248 \\
\hline Lungimea lemniscului stâng & 0,704 & 0,055 & 0,111 & 15,7 & 5,7 & 0,593 & 0,855 \\
\hline Lățimea lemniscului stâng & 0,230 & 0,018 & 0,037 & 16,0 & 5,8 & 0,187 & 0,277 \\
\hline Lungimea ouălor & 0,088 & 0,005 & 0,012 & 14,0 & 3,8 & 0,065 & 0,099 \\
\hline Lățimea ouălor & 0,011 & 0,0007 & 0,002 & 16,6 & 4,6 & 0,008 & 0,013 \\
\hline
\end{tabular}

Notă: MS - eroarea mediei, $\sigma$ - abaterea mediei pătratică, CV - coeficientul de variație, sdCV - eroarea coeficientului de variație. 
Amfibienii pentru specia Acanthocephalus ranae Schrank, 1788 sunt gazde definitive. Gazde intermediare sunt crustaceele Ostracoda, Amphipoda și Isopoda acvatice și măgărușul-de-apă (Asellus aquaticus).

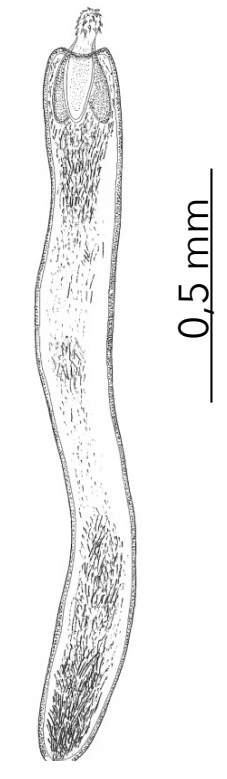

a

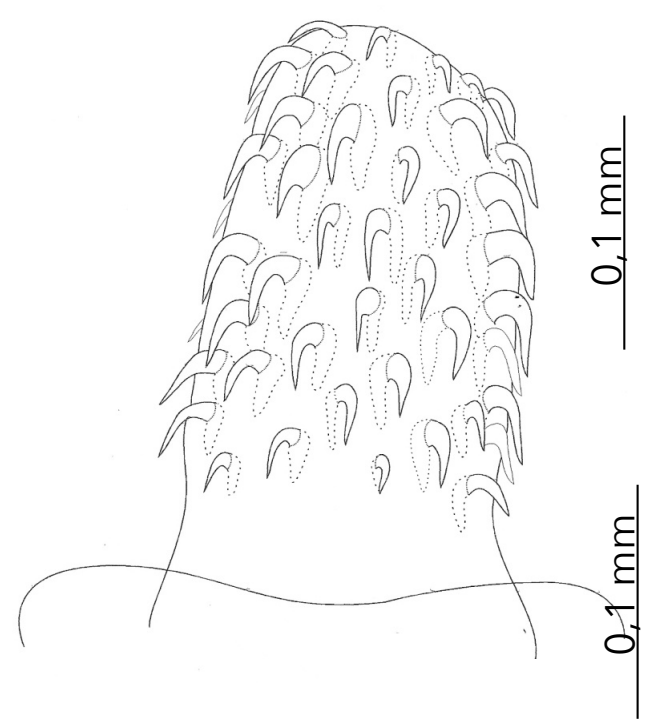

b

Figura 2. Acanthocephalus ranae Schrank, 1788: a - femelă, aspectul general, $b$ - proboscisul

\section{CONCLUZII}

1. Pentru prima dată în Republica Moldova s-au efectuat cercetări cu referire la stabilirea faunei acantocefalice la amfibienii complexului Pelophylax esculenta și descrierea parametrilor morfometrici.

2. La investigarea helmintologică a 360 de specimene ale complexului Pelopohylax esculenta s-au obținut 86 de exemplare de Acanthocephalus ranae care au fost obținute de la specia Pelophylax ridibundus colectată din lacurile nr. 1, 2 - Ciuciuleni, nr. 10 - Rezervația "Codrii", din lacul de la mănăstirea Hâncu, Ghidighici și Valea Trandafirilor; P. lessonae - din lacurile nr. 2 - Ciuciuleni, nr. 10, 11 - Rezervația "Codrii", lacul de la Mănăstirea Hâncu și Ghidighici și P.esculentus colecta- 
tă din lacul de la Mănăstirea Hâncu și lacul Ghidighici.

3. S-a determinat încadrarea taxonomică a speciei Acanthocephalus ranae și s-a stabilit că aparține clasei Palaeacanthocephala, ordinul Echinorhynchida, familia Echinorhynchidae și genul Acanthocephalus.

4. S-a stabilit că la speciile complexului Pelophylax esculenta, specia de acantocefale Acanthocephalus ranae Schrank, 1788 își are specificitatea organică în intestinul subțire.

Investigațiile au fost realizate în cadrul proiectului 15.817.02.12 F și 16.80012.02.16F finanțate de Consiliul Suprem pentru Știință și Dezvoltare Tehnologică al Academiei de Științe a Moldovei.

\section{BIBLIOGRAFIE}

1. Lisitsyna, O.I. Taxonomic and ecology diversity of acanthocephalans of the fauna of Ukraine. In: Proceedings of the V Congress of Russian Society of Parasitologists of the Russian Academy of Sciences, Novosibirsk, 2013, p. 107.

2. АнАрейко, О.Ф. Паразиты млнкопитающих Молдавии. ИзАателъство "Штиинца" Кишинев, 1973. 176 с.

3. Матвеева Е.А., Индирякова Т.А. Биологическое разнообразие гельминтофауны Rana ridibunda в урбанизированной экосистеме. Российская Академия Естествознания. Научный журнал «Современные наукоемкие технологии». 2009, №3. - С. 67-68.

4. Петроченко В.И. Акантоцефалы домашних и диких животных. И-во Академии наук СССР. Москва, 1956, Том 1. - 435 с.

5. Рыжиков К. М., Шарпило В. П. Шевченко Н. Н. Гельминты амфибий фауны СССР. М., 1980. 279 c.

6. Сергиев В.П. Методы санитарно-паразитологической экспертизы рыбы, моллюсков, ракообразных, земноводных, пресмыкающихся и продуктов их переработки: методич. указания. М.: Федеральный центр госсанэпиднаАзора МинзАрава России, 2001. - 69 с.

7. Спирина Е.В. Амфибии как биоиндикационная тест-система Аля экологической оценки водной среды обитания: Автореф. Аис. канА. биол. наук. Ульяновск, 2007. -23 c.

8. Скрябин К.И. МетоА полных гельминтологических вскрытий позвоночных, вк^ючая человека. М. ИзА-во МГУ 1928. - 45 с. 